\title{
GESTÃO DE TURISMO DE EVENTOS: REFLEXÕES SOBRE OS EVENTOS DA REGIÃO CENTRAL DO RIO GRANDE DO SUL/BRASIL
}

\author{
EVENTS TOURISM MANAGEMENT: REFLECTIONS ON THE EVENTS OF \\ THE CENTRAL REGION OF RIO GRANDE DO SUL/BRAZIL
}

\author{
Dalva Maria Righi Dotto ${ }^{1}$, Monica Elisa Dias Pons², \\ José Martinho Rodrigues Remedi ${ }^{3}$ e Lilian Coradini Cerezer ${ }^{4}$
}

Recebido em: 20/04/2016 Aprovado em: 12/09/2016

\section{RESUMO}

São recorrentes os estudos, os levantamentos e a elaboração de planos para o turismo nas diferentes instâncias do setor público e privado. No Rio Grande do Sul, a Secretaria Estadual de Esporte, Turismo e Lazer (SETEL) divide o estado em regiões para definir com mais precisão as políticas públicas e a organização do setor. Com ênfase no tema turismo de eventos e utilizando como recorte geográfico a região central do Rio Grande do Sul, por meio de uma pesquisa exploratória e qualitativa, objetivou-se sistematizar os eventos divulgados pela SETEL, com análise por município e região, e, mais especificamente, verificar os principais aspectos referentes aos organizadores, aos tipos, à abrangência e à periodicidade dos eventos e à categorização dos municípios realizada pelo Ministério de Turismo. Os resultados da pesquisa demonstraram que são poucos os organizadores de eventos que utilizam o website da SETEL para divulgar e atrair turistas, ferramenta essa que é disponibilizada gratuitamente pela Secretaria de Turismo. Também se constatou que a maioria dos eventos tem periodicidade anual, ocorrendo, sobretudo, no segundo semestre, e que as parcerias entre setor público e privado para a realização de eventos ainda é incipiente na região estudada.

Palavras-chave: gestão do turismo; turismo de eventos; regionalização do turismo.

\begin{abstract}
There are recurring studies, surveys and plans for tourism, in different public and private sectors. In Rio Grande do Sul, the state Department of Sport, Tourism and Leisure (SE$T E L)$ divides the state into regions to define more precisely the policies and organization of the sector. With an emphasis on the theme of events tourism and using as a geographical cut the Central region of Rio Grande do Sul, this study was conducted through an exploratory research, with a qualitative research approach and aimed to systematize the events disclosed by SETEL, with analysis by municipality and region. More precisely, the study aimed to verify the main aspects concerning the identification of the organizers, event types, scope, frequency and categorization of municipalities conducted by the Ministry of Tourism. The survey results showed that there are few event planners who use SETEL's website to publicize and attract tourists, despite the fact that this tool is provided for free by this Department. It was also evident that most of the events are annual, that there is a higher concentration in the second semester of the year and those partnerships between public and private sectors for the realization of events is still incipient in the region studied.
\end{abstract} Keywords: tourism management; events tourism; tourism regionalization.

\footnotetext{
1 Doutora em Desenvolvimento Regional. Graduada em Administração. Docente Adjunta da UDESSM/UFSM. Coordenadora do Curso de Administração da UDESSM/UFSM. E-mail: dalvadotto@gmail.com

2 Doutora em Comunicação Social. Docente Adjunta da UDESSM/UFSM. E-mail: monica@ufsm.com

3 Doutor em História; Docente Adjunto da UFSM. E-mail: jose.remedi@gmail.com

4 Graduanda em Administração - UDESSM/UFSM. E-mail: liliancerezer@hotmail.com 


\section{Introdução}

A proliferação de megaeventos em escala mundial colocou em evidência o fenômeno dos eventos como objeto de reflexão para diferentes áreas acadêmicas. Atualmente, as pesquisas sobre as características, as dificuldades e as potencialidades dos eventos em suas múltiplas escalas vão do planejamento e da administração aos aspectos históricos e culturais, passando pela análise de impactos sociais e ambientais e, é claro, tendo se tornado um segmento especializado do setor turístico. Dessa forma, os eventos são um dos motivadores mais importantes do turismo e, também, um relevante impulsionador da elaboração e comercialização de pacotes turísticos baseados em destinos. É farta a literatura que documenta a atividade e os impactos dos eventos planejados - em especial, dos megaeventos - e a disputa por eventos sazonais, tais como as Olimpíadas, a Copa do Mundo de Futebol e os Festivais de Música, entre cidades e países (HORNE e MANZENREITER, 2006; DaCOSTA, 2008; BAHL, 2004; BARBOSA e SCAVARDA, 2015). No entanto, como afirma Getz,

foi apenas algumas décadas atrás, que "o turismo de eventos" se estabeleceu, tanto na indústria do turismo como na comunidade de pesquisa, de modo que o crescimento subsequente deste setor só pode ser descrito como espetacular (GETZ, 2008, p. 403, grifo do autor, tradução nossa).

O turismo de eventos, entre as demais possibilidades da atividade turística, tem se destacado cada vez mais por possibilitar alterações significativas no local de sua destinação. Os organizadores dos eventos elencam estímulos ao desenvolvimento social e econômico e à geração de renda e de empregos. Instituiu-se, por exemplo, o termo "legado" associado às campanhas de marketing para as comunidades receptoras dos eventos, referindo-se às melhorias para a população das cidades que recebem megaeventos.
Pode-se dizer que a importância dos eventos no turismo está na própria origem da atividade, que foi criada pelo fato de existirem deslocamentos motivados por eventos. Na atualidade, há um crescimento do turismo de eventos em níveis globais. $\mathrm{O}$ fenômeno dos eventos vem aumentando em número, em diversidade e em popularidade, variando em escala dos megaeventos aos pequenos festivais comunitários (SMALL, 2007).

Os poderes públicos, em seus diversos níveis, organizam eventos: os estados nacionais, para públicos estrangeiros como forma de promoção e divulgação de seus países, e os governadores e os dirigentes municipais, para divulgar suas comunidades e seus atrativos locais como possíveis destinos turísticos, tendendo a vincular os eventos com pautas da política econômica, social e, às vezes, em segundo plano, artística $\mathrm{e}$ cultural. Nesse contexto, os eventos são uma forma utilizada pelas empresas de marketing para fazer a promoção de seus produtos em certas ocasiões, como, por exemplo, em comemorações de empresas, feiras de negócios, eventos esportivos e espetáculos artísticos.

Tendo isso em vista, este estudo se concentra na região central do Rio Grande do Sul, utilizando como referência a divisão por regiões realizada pela Secretaria Estadual de Esporte, Turismo e Lazer (SETEL) no Plano de Desenvolvimento do Turismo do Rio Grande do Sul - 2012-2015, a fim de sistematizar e analisar, por município e região, o turismo de eventos, considerando os eventos divulgados no website da SETEL em 2015. As análises contemplam aspectos referentes aos organizadores, aos tipos, à abrangência e à periodicidade dos eventos, além da categorização dos municípios realizada pelo Ministério de Turismo, que resulta da soma das variáveis de desempenho econômico relativo às atividades de turismo, constante no Mapa do Turismo Brasileiro. 


\section{Turismo de eventos: noções gerais e tipologias}

A ideia de eventos em geral está associada à perspectiva de festejar, comemorar, celebrar algo ou alguém, acontecimento que busca atrair a atenção e despertar o interesse de determinado público-alvo sobre uma ação específica. Por muito tempo, os eventos foram entendidos como atividades meramente práticas, no entanto, configuram-se com uma tarefa complexa e que envolve muitas responsabilidades. Nas últimas décadas, o conceito de eventos e seus desdobramentos em torno das etapas de planejamento, organização, execução, avaliação e pós-evento têm proporcionado discussões profícuas no meio acadêmico.

Partindo-se dessa realidade inegável do desenvolvimento de eventos na área do turismo pelo mundo inteiro, podemos verificar, também, que os eventos se caracterizam pela necessidade de divulgar e de destacar alguma ação pontual relacionada a determinada temática. Para Andrade,

o evento organizado, como atividade econômica, igual a qualquer outra, precisa ser dimensionado, avaliando-se o nível atual de mercado e projetando-se a possibilidade de sua realização, nunca esquecendo os caracteres subjetivos impregnados na sociedade em que se pretende realizar o evento (ANDRADE, 2007, p. 116).

A atividade de eventos configurase cada vez mais como um instrumento de promoção de destinos turísticos.

Do ponto de vista do consumidor, ou da audiência, um evento especial é a oportunidade para o lazer, para uma experiência social ou cultural fora da rotina diária. Do ponto de vista do organizador, um evento especial é um acontecimento único e não frequente, fora do padrão normal das atividades. O que é "especial" para o organizador pode não ter nenhum interesse para os consumidores em potencial, assim, de uma perspectiva de marketing, o produto deve ser comparado com segmentos cuidadosamente definidos (GETZ, 2001, p. 425, grifo do autor).

Dessa forma, em diversas sociedades, o turismo de eventos apresentase como uma promissora atividade para alavancar o crescimento econômico e social das comunidades nas quais se realiza. No entendimento de Marujo,

o planejamento e organização de eventos surgem como uma "arma" para combater a chamada sazonalidade turística de muitos destinos. De fato, os efeitos da sazonalidade do turismo podem ser minimizados através da promoção e realização de eventos, uma vez que podem atrair turistas nos períodos do ano em que a procura é normalmente baixa (2014, p. 26, grifo do autor).

A autora afirma, ainda, que os eventos funcionam como verdadeiros instrumentos de promoção de uma região como destino turístico, ressaltando que devem ser bem planejados e divulgados para gerarem uma imagem positiva e promoverem o destino em questão. O turismo de eventos apresenta-se como uma oportunidade para um município, uma região ou um país em função das potencialidades de desenvolvimento social, econômico e cultural, entre outros. Além disso, dinâmica do turismo de eventos pode desencadear mudanças na rotina de determinada localidade, na medida em que essa movimentação estimula o ramo da gastronomia, da hospedagem, do transporte e de demais setores que interligam uma localidade. O turista de eventos, muitas vezes, mescla interesses profissionais e de lazer (congressos, convenções, seminários e feiras), tornando-se um consumidor em potencial e que pode, em um futuro próximo, retornar com a família e os amigos, divulgando mais um destino turístico. Daí a importância de bem planejar 
e gerir os eventos para que os impactos sejam mais positivos que negativos.

Cada evento possui uma especificidade, sendo importante, para que o processo de organização transcorra de forma harmoniosa, que os objetivos propostos estejam claros, pois estes representam o eixo norteador da execução de todas as atividades a serem realizadas - um evento sem objetivos claros pode significar esforço humano, tempo e recursos desperdiçados. No setor de turismo, existem diferentes formas de atrair os consumidores, de acordo com as motivações impulsionadoras, no processo de decisão para a aquisição de produtos turísticos. Segundo Montejano (2001), as principais motivações dos turistas são a necessidade de repouso, diversão, lazer e interação com novas culturas.

Nesse contexto, o turismo de eventos, considerado por Meirelles (1999) como uma forma de reunião, é definido mais detalhadamente por $\mathrm{Za}-$ nella (2004, p. 69) como uma concentração ou reunião formal e solene de pessoas e/ou entidades realizada em data e local especial, com o objetivo de celebrar acontecimentos importantes e significativos e estabelecer contatos de natureza comercial, cultural, esportiva, social, familiar religiosa, etc.

Tornou-se cada vez mais perceptível que os eventos são catalizadores de mudanças nas comunidades envolvidas, impulsionando avanços nos transportes, nas comunicações, na hotelaria, na gastronomia e no comércio de bens e serviços da região. Devido ao crescimento da relevância, dinâmica e diversificação e ao impacto econômico no desenvolvimento social, foram definidas tipologias de eventos. Nesse contexto, Getz (2008) propõe uma tipologia das principais categorias de eventos, com base, principalmente, em sua forma, isto é, nas diferenças óbvias em seu propósito e programa (Quadro 1).

Quadro 1 - Tipologia do turismo de eventos

\begin{tabular}{|c|c|c|}
\hline CULTURAIS & NEGÓCIOS E COMÉRCIO & ESPORTES E \\
- Festivais & COMPETIÇÕES \\
- Carnaval & - Reuniões & \\
- Comemorações & - Convenções & - Amadores/Profissionais \\
- Eventos religiosos & - Exposiras & - Espectadores/Participantes \\
POLÍTICOS E ESTATAIS & EDUCACIONAIS E & \\
- Reuniões de cúpula & CIENTÍFICOS & RECREACIONAIS \\
- Eventos políticos & - Conferências & - Esporte e jogos por \\
- Ocasiões especiais & - diversão \\
- Visitas de VIPs & - Oficinas & \\
ARTES E & - Treinamento & PARTICULARES/ \\
ENTRETENIMENTO & & PRIVADOS \\
- Concertos & & - Casamentos \\
- Espetáculos & & - Festas \\
Cerimônias de premiação & & - Reuniões sociais \\
\hline
\end{tabular}

Fonte: adaptado de Getz (2008, p. 404, tradução nossa). 


\begin{abstract}
Ainda segundo Getz,
alguns [eventos] são para celebração pública (esta categoria inclui os chamados "festivais comunitários", que normalmente contêm uma grande variedade em sua programação e visam fomentar o orgulho e a coesão cívica), enquanto outros estão previstos para fins de concorrência, divertimento, entretenimento, negócios ou socialização. Muitas vezes, eles exigem instalações para fins especiais, e os gestores dessas instalações (como centros de convenções e arenas esportivas) visam tipos específicos de eventos (2008, p. 405, grifo do autor, tradução nossa).
\end{abstract}

Outra classificação dos eventos é apresentada por Matias (2010), com base nas áreas de interesse envolvidas: Artístico, Científico, Cultural, Cívico, Desportivo, Folclórico, Lazer, Promocional, Religioso e Turístico.

A partir das duas classificações apresentadas, entre outras existentes, pode-se ver a amplitude do fenômeno do turismo de eventos e da necessidade de tratá-lo como um complexo e multifacetado objeto de investigação acadêmica.

\subsection{Gestão e impactos do turismo de eventos}

Um aspecto importante para a realização de eventos é o seu adequado pla- nejamento e a sua profissional execução. Para Kotler e Armstrong (2003), eventos devem ser entendidos como ocorrências que são planejadas e que objetivam transmitir mensagens para públicos-alvo. Dessa forma, shows, exibições e excursões, por exemplo, devem ser compreendidos como canais de comunicação não pessoal.

Diversas áreas, dentre as quais administração, economia, geografia e antropologia, têm estudado a atividade turística nos diferentes aspectos da sociedade. Estas pesquisas, segundo Barreto,

permitem relativizar a influência do fenômeno em relação à dos meios de comunicação (no caso da questão cultural) e em relação a outras indústrias (no caso da poluição ambiental), sem contar que evidenciam o importante papel que o turismo vem tendo na recuperação do patrimônio histórico, dos museus, da cultura popular e das tradições (2004, p. 85).

É perceptível que o turismo de eventos exerce papel relevante nos campos econômico, cultural e social. No entanto, não se deve idealizar o fato de que todas as influências sejam positivas (Quadro 2). Afinal, no turismo os impactos "[...] referem-se à gama de modificações ou sequência de eventos provocados pelo processo de desenvolvimento turístico nas localidades receptoras" (RUSCHMANN, 2000, p. 34). 
Quadro 2 - Exemplos de impactos do turismo

\begin{tabular}{|c|c|c|}
\hline Subsistemas & Impactos Positivos & \begin{tabular}{|l|} 
Impactos Negativos \\
\end{tabular} \\
\hline $\begin{array}{l}\text { Ambiente } \\
\text { Natural }\end{array}$ & $\begin{array}{l}\text { - Alertar a consciência para o patri- } \\
\text { mônio natural existente }\end{array}$ & $\begin{array}{l}\text { - Poluição } \\
\text { - Sobrecarga dos espaços, equipa- } \\
\text { mentos e serviços urbanos (exem- } \\
\text { plos: parques, praias e serviços de } \\
\text { saúde) }\end{array}$ \\
\hline $\begin{array}{l}\text { Ambiente } \\
\text { Sociocultural }\end{array}$ & $\begin{array}{l}\text { - Intercâmbio cultural e conhecimen- } \\
\text { to de etnias e crenças diferentes } \\
\text { - Partilha de valores } \\
\text { - Aumento da tolerância entre popu- } \\
\text { lações } \\
\text { - Valorização do que é genuíno de } \\
\text { cada cultura e patrimônio } \\
\text { - Aumento do orgulho pela região e } \\
\text { cultura local }\end{array}$ & $\begin{array}{l}\text { - Sobrecarga populacional } \\
\text { - Segregação social } \\
\text { - Perda da identidade das popula- } \\
\text { ções locais } \\
\text { - Destruição de estruturas sociais } \\
\text { - Congestionamento das atrações } \\
\text { turísticas (exemplos: transportes e } \\
\text { infraestruturas) } \\
\text { - Intensificação dos problemas de } \\
\text { segurança pública (drogas, furtos } \\
\text { e roubos) }\end{array}$ \\
\hline $\begin{array}{l}\text { Ambiente } \\
\text { Econômico }\end{array}$ & $\begin{array}{l}\text { - Aumento de postos de trabalho } \\
\text { - Aumento do rendimento de famílias } \\
\text { - Aumento das trocas comerciais com } \\
\text { o exterior } \\
\text { - Aumento das receitas fiscais } \\
\text { - Melhoria de infraestruturas } \\
\text { - Desenvolvimento de outros setores } \\
\text { da economia }\end{array}$ & \\
\hline
\end{tabular}

Fonte: adaptado de Cardoso (2013, p. 23).

É indispensável que todo planejamento de evento leve em consideração a aplicação de metodologias de avaliação e prevenção de impactos nas comunidades envolvidas. Esse é um trabalho que ultrapassa a organização do evento e deve envolver de múltiplas formas diferentes agentes governamentais, privados e comunitários. A administração pública deve licenciar e fazer cumprir as exigências legais, os empreendedores devem minimizar ao máximo seus impactos negativos, cumprir as leis e respeitar a cultura, e a comunidade deve fiscalizar e participar das discussões exigindo seus direitos.

Com integração e participação dos diferentes agentes envolvidos, temse a possibilidade de que o turismo de eventos seja propiciador de desenvolvimento local e regional. Mas, também, "é importante reconhecer que os eventos contêm valores que ultrapassam os simples impactos econômicos positivos" (MARUJO, 2015, p. 10).
Afinal, como afirmam Allen e colaboradores,

O homem é um animal social e as celebrações exercem um papel-chave no bem-estar da estrutura social. Os eventos podem engendrar coesão, confiança e autoestima social. Eis a fonte do seu poder e da sua influência política, e a razão pela qual os eventos sempre irão refletir e interagir com as suas circunstâncias políticas e meio ambiente (2003, p. 17).

É um ponto comum nos trabalhos que tematizam o turismo de eventos verificar os impactos econômicos positivos e a alavancagem do desenvolvimento local. No entanto, cada vez mais, surgem novos indicadores que mostram as consequências socioculturais negativas, assim como os efeitos danosos ao ambiente - estes aspectos exigem maiores pesquisas (GETZ, 2008). Muito embora pareça óbvio que os eventos turísticos 
provocam impactos positivos e negativos em várias esferas das comunidades nas quais se desenvolvem, sempre é importante ressaltar que os organizadores de eventos devem ter a preocupação de identificar e gerir esses impactos, que as autoridades devem regrar e fiscalizar essas atividades e que as populações atingidas devem ser consultadas.

\section{Procedimentos metodológicos}

Para estudar a dinâmica de realização de eventos, optou-se por uma abordagem qualitativa (MALHOTRA, 2011), de natureza descritiva, por meio de técnica de levantamento de dados secundários. Mattar (1996) destaca que a pesquisa descritiva tem a função de descrever características de grupos e verificar a existência de relações entre as variáveis, podendo ser aplicada à pesquisa documental, de estudo de campo, de levantamento, entre outras. Neste estudo, foi realizada uma investigação, por meio de um levantamento de dados nos websites oficiais do Ministério do Turismo e da SETEL. Como recorte geográfico, o estudo utilizou como referência a divisão em regiões turísticas da referida Secretaria de Estado, concentrando-se na região denominada central.

Nos referidos websites, os dados utilizados neste estudo são disponibilizados por município e de forma dispersa. Inclusive, embora a denominação da Secretaria Estadual responsável pelo setor de turismo no Rio Grande do Sul já tenha sido alterada de Secretaria Estadual de Turismo (SETUR) para Secretaria Estadual de Turismo, Esporte e Lazer (SETEL), desde o início de 2015, ainda são mantidos e atualizados dois websites oficiais (SETUR, 2016; SETEL, 2016).

A proposta deste estudo de sistematizar os dados foi realizada por meio da organização de informações no intuito de possibilitar uma análise comparativa. Nessa perspectiva, do Ministério do Turismo foram extraídos dados relacionados à categorização dos municípios brasileiros quanto ao quesito atividade turística, a fim de estabelecer uma comparação entre os municípios da região em relação ao Rio Grande do Sul e ao Brasil. Dos websites SETEL e SETUR, os dados coletados referentes aos eventos divulgados e realizados no ano de 2015 foram utilizados para realizar a comparação entre os municípios da região, contemplando as seguintes variáveis: abrangência do evento (microrregional, regional, estadual, nacional e internacional); tipo de evento (feiras e exposições, religioso, gastronômico, rodeio, carnaval e esportivo); e entidade organizadora do evento (Prefeitura, Associações, Instituições privadas, Instituições religiosas e Instituições públicas). Também foram comparados dados referentes à quantidade de eventos divulgados no website da SETEL, ao período de ocorrência e à periodicidade da realização desses eventos.

\section{Resultados e discussões}

\subsection{A regionalização do turismo no Rio} Grande do Sul

A delimitação de regiões é determinada segundo os fins a que se propõe. Nesta perspectiva, a regionalização turística do Rio Grande do Sul, presente no Plano de Desenvolvimento do Turismo do Rio Grande do Sul - 2012-2015, foi elaborada pela SETEL, com o objetivo de empoderamento destas importantes instâncias de governança [...] essas instâncias devem promover o desenvolvimento do turismo local, fomentando a criação de colegiados municipais de turismo com representantes do poder público, privado e da sociedade civil organizada, e se articulando com outras instâncias de governança e atores envolvidos com o desenvolvimento do turismo em sua região (2012).

Como política pública no setor de turismo, o estado foi dividido em 11 
regiões (Figura 1) e 23 microrregiões: (a) Grande Porto Alegre - Porto Alegre e Delta do Jacuí (oito municípios); Vale do Rio dos Sinos (12 municípios); (b) Serra Gaúcha - Hortênsias (cinco municípios), Vale do Paranhana (seis municípios), Uva e Vinho (33 municípios), Campos de Cima da Serra (oito municípios) e Rota das Araucárias (20 municípios); (c) Litoral Norte Gaúcho - Litoral Norte Gaúcho (23 municípios); (d) Hidrominerais - Cultura e Tradição (12 municípios), Rota Águas e Pedras (23 municípios) e Termas e Lagos (16 municípios); (e) Rota das
Terras - Rota das Terras (22 municípios); (f) Yucumã - Rota do Yucumã (33 municípios); (g) Missões - Rota do Rio Uruguai (20 municípios) e Rota Missões (26 municípios); (h) Central Central (35 municípios); (i) Vales - Vale do Rio Pardo (22 municípios), Vale do Taquari (38 municípios) e Vale do Caí (20 municípios); (j) Costa Doce - Sul (14 municípios), Centro-Sul (14 municípios), Campanha (sete municípios) e Fronteira Gaúcha (nove municípios); e (1) Pampa Gaúcho - Campanha (sete municípios) e Fronteira Gaúcha (nove municípios) (SETUR/RS, 2015). 
Figura 1 - Mapa das regiões turísticas do estado do Rio Grande do Sul

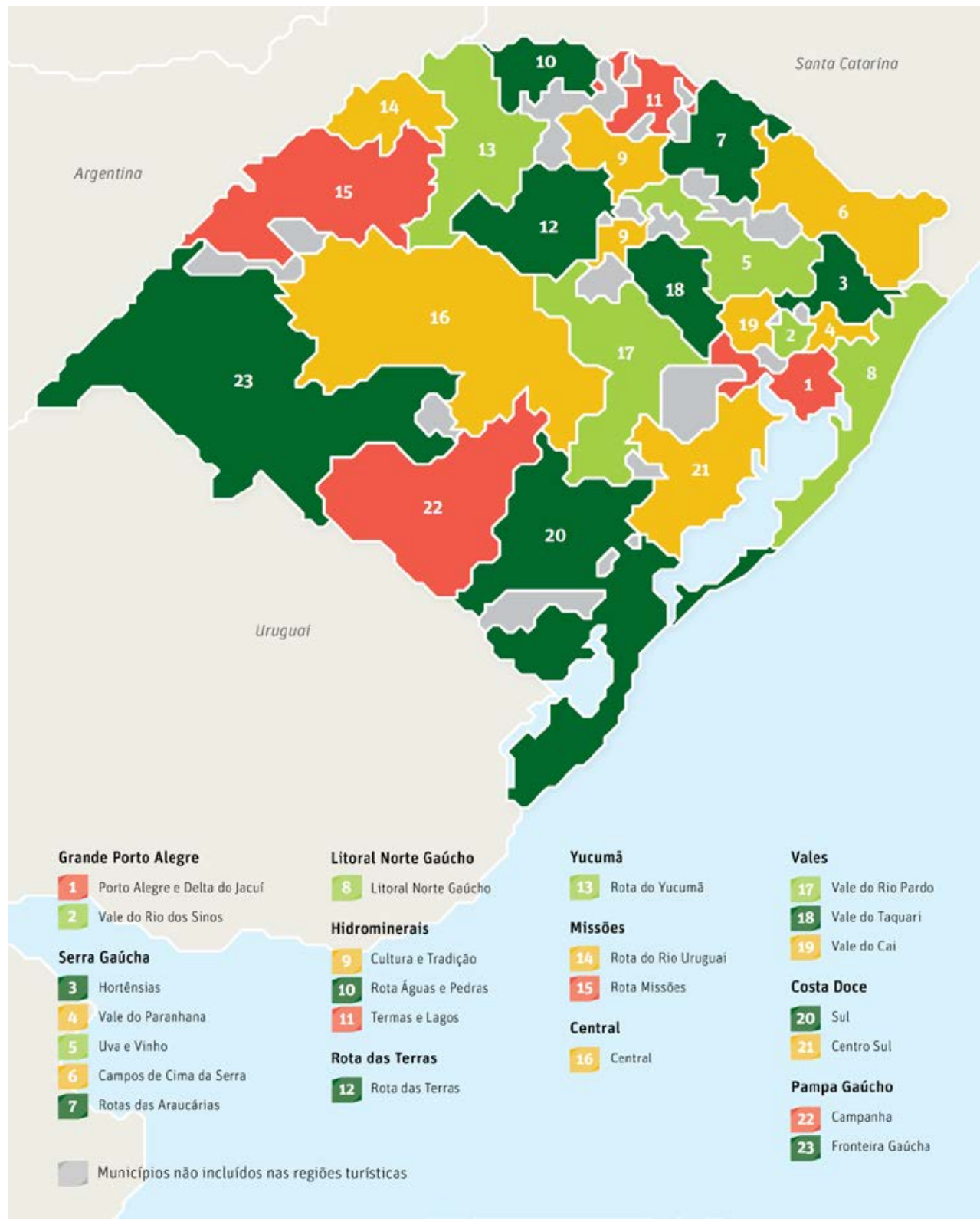

Fonte: RIO GRANDE DO SUL (2012, p. 31). 
4.2 Características da região central do Rio Grande do Sul no quesito turismo

A região central (delimitada no item 16 da Figura 1) concentra 35 municípios, 652.277 habitantes, 9,3 bilhões do Produto Interno Bruto (PIB), 94 locais de hospedagem, 35 agências de viagem e operadoras e 599 estabelecimentos de alimentos e bebidas (A\&B). Os municípios que pertencem a essa região são Agudo, Cacequi, Cachoeira do Sul, Capão do Cipó, Cerro Branco, Dilermando de Aguiar, Dona Francisca, Faxinal do Soturno, Formigueiro, Itaara, Ivorá, Jaguari, Jari, Júlio de Castilho, Mata, Nova Esperança do Sul, Nova Palma, Novo Cabrais, Paraíso do Sul, Pinhal Grande, Quevedos, Restinga Seca, Santa Maria, Santiago, São Francisco de Assis, São João do Polêsine, São Martinho da Serra, São Pedro do Sul, São Sepé, São Vicente do Sul, Silveira Martins, Toropi, Tupanciretã, Unistalda e Vila Nova do Sul (SETUR/RS, 2015).

Os principais destaques da região central, no setor de turismo, são a gastronomia italiana na Quarta Colônia, os sítios zoobotânicos e paleontológicos e o turismo religioso. $\mathrm{O}$ polo econômico, cultural, tecnológico, acadêmico e logístico da região encontra-se no município de Santa Maria, e as principais atrações são a Rota Turística e Gastronômica Santa Maria-Silveira Martins, os antigos fósseis de dinossauros, que atraem interesse de grupos de visitantes e de pesqui- sadores, e a Rota Santos Caminhos da Fé (que inclui cinco municípios da região central e municípios da região das Missões) (SETEL/RS, 2015).

Ressalta-se que o Mapa do Turismo Brasileiro prevê cinco categorias, de A até E, que são o resultado da soma das variáveis de desempenho econômico, considerando o número de estabelecimentos formais cuja atividade principal é hospedagem; o número de empregos formais no setor de hospedagem; a estimativa de turistas a partir do Estudo de Demanda Doméstica; e a estimativa de turistas a partir do Estudo de Demanda Internacional. Essa categorização classificou os 3.345 municípios do Mapa do Turismo Brasileiro, a fim de auxiliar na implementação de políticas públicas mais eficientes, distinguindo as peculiaridades e especificidades de cada região, para uma melhor compreensão do envolvimento de cada município no processo de desenvolvimento regional do turismo (BRASIL, 2015).

Considerando a categorização dos municípios do Mapa do Turismo Brasileiro, realizada pelo Ministério do Turismo, pode-se perceber que, na região central do Rio Grande do Sul, não há municípios enquadrados na categoria A. O município de Santa Maria foi incluído na categoria $\mathrm{B}$, o município de Cachoeira do Sul, na categoria C, e a maioria dos municípios enquadra-se na categoria $\mathrm{D}$, com alguns incluídos na $\mathrm{E}$ (Quadro 3) (BRASIL, 2015). 
Quadro 3 - Categorização dos municípios da região central do Rio Grande do Sul - 2015

\begin{tabular}{|c|c|c|c|}
\hline Municípios & $\begin{array}{c}\text { Categorização } \\
\text { dos municípios }\end{array}$ & Municípios & $\begin{array}{c}\text { Categori- } \\
\text { zação dos } \\
\text { municípios }\end{array}$ \\
\hline 1. Agudo & $\mathrm{D}$ & 19. Paraíso do Sul & $\mathrm{E}$ \\
\hline 2. Cacequi & $\mathrm{D}$ & 20. Pinhal Grande & $\mathrm{E}$ \\
\hline 3. Cachoeira do Sul & $\mathrm{C}$ & 21. Quevedos & $\mathrm{E}$ \\
\hline 4. Capão do Cipó & $\mathrm{D}$ & 22. Restinga Seca & $\mathrm{D}$ \\
\hline 5. Cerro Branco & $\mathrm{E}$ & 23. Santa Maria & $\mathrm{B}$ \\
\hline 6. Dilermando de Aguiar & $\mathrm{D}$ & 24. Santiago & $\mathrm{C}$ \\
\hline 7. Dona Francisca & $\mathrm{E}$ & 25. São Francisco de Assis & $\mathrm{D}$ \\
\hline 8. Faxinal do Soturno & $\mathrm{D}$ & 26. São João do Polêsine & $\mathrm{D}$ \\
\hline 9. Formigueiro & $\mathrm{D}$ & 27. São Martinho da Serra & $\mathrm{E}$ \\
\hline 10. Itaara & $\mathrm{E}$ & 28. São Pedro do Sul & $\mathrm{D}$ \\
\hline 11. Ivorá & $\mathrm{D}$ & 29. São Sepé & $\mathrm{D}$ \\
\hline 12. Jaguari & $\mathrm{D}$ & 30. São Vicente do Sul & $\mathrm{D}$ \\
\hline 13. Jari & $\mathrm{E}$ & 31. Silveira Martins & $\mathrm{D}$ \\
\hline 14. Júlio de Castilhos & $\mathrm{D}$ & 32. Toropi & $\mathrm{E}$ \\
\hline 15. Mata & $\mathrm{D}$ & 33. Tupanciretã & $\mathrm{D}$ \\
\hline 16. Nova Esperança do Sul & $\mathrm{D}$ & 34. Unistalda & $\mathrm{E}$ \\
\hline 17. Nova Palma & $\mathrm{D}$ & 35. Vila Nova do Sul & $\mathrm{D}$ \\
\hline 18. Novo Cabrais & $\mathrm{E}$ & & \\
\hline Fona & & & \\
\hline adaptado de Brasil 2015 . & & \\
\hline
\end{tabular}

Fonte: adaptado de Brasil (2015).

Em análise comparativa entre a região central do Rio Grande do Sul, o estado do Rio Grande do Sul e o Brasil, percebe-se que a região central desse estado concentra, proporcionalmente, mais municípios na categoria $\mathrm{E}$, apresentando índices menores nas categorias
A, B e C. Com base nesse mapeamento, é possível afirmar que os municípios da região central possuem menos representatividade de atividade turística, no quesito desempenho econômico, do que a média apresentada no Brasil e no Rio Grande do Sul (Quadro 4).

Quadro 4 - Classificação, por categoria, dos municípios do Brasil, do Rio Grande do Sul e da região central - 2015

\begin{tabular}{|c|c|c|c|c|c|c|}
\hline \multirow[t]{2}{*}{ Categoria } & \multicolumn{2}{|c|}{ Brasil } & \multicolumn{2}{|l|}{$\mathbf{R S}$} & \multicolumn{2}{|c|}{ Região central } \\
\hline & $\begin{array}{l}\text { N. }{ }^{o} \text { municí- } \\
\text { pios }\end{array}$ & $\%$ & N. ${ }^{\circ}$ municípios & $\%$ & N. ${ }^{\circ}$ municípios & $\%$ \\
\hline $\mathrm{A}$ & 51 & 1,52 & 3 & 0,64 & 0 & 0 \\
\hline $\mathrm{B}$ & 167 & 4,99 & 13 & 2,78 & 1 & 2,9 \\
\hline $\mathrm{C}$ & 04 & 15,1 & 39 & 8,35 & 2 & 5,7 \\
\hline $\mathrm{D}$ & 1841 & 55,04 & 227 & 48,6 & 21 & 60,0 \\
\hline$E$ & 782 & 23,38 & 185 & 39,6 & 11 & 31,4 \\
\hline Total & 3345 & 100 & 467 & 100 & 35 & 100 \\
\hline
\end{tabular}

Fonte: adaptado de Brasil (2015). 
4.3 O turismo de eventos na região central do Rio Grande do Sul

Quando um consumidor pretende realizar alguma atividade que envolve a escolha de um produto turístico, inicia a coleta de informações, no intuito de avaliar as alternativas existentes. Essa busca de informações é parte do processo de decisão de compra do consumidor, que compreende os estágios de (a) pré-compra, com as etapas de estímulo, conscientização do problema, busca de informações e avaliação das alternativas; (b) consumo; e (c) pós-compra (KOTLER e KEPLER, 2012; HOFFMANN e BATSON, 2006; BOONE e KURTZ, 2009).

Como o sucesso de um evento pressupõe a atração de pessoas para usufruir da programação, a comunicação entre o organizador e o consumidor é requisito relevante para atingir os objetivos dos proponentes e dos turistas. A comunicação "visa informar, persuadir ou lembrar os clientes sobre um serviço que está sendo oferecido", e, portanto, "não se pode esperar que os clientes usem um serviço que desconhecem" (HOFFMANN e BATSON, 2006, p. 215).

Utilizada de forma mais intensa atualmente, a comunicação via internet reflete a mudança do comportamento do consumidor, que busca informações com praticidade e rapidez (TORRES, 2010). Nesse contexto, o uso das mídias interativas eletrônicas possibilita atingir uma grande audiência e é uma forma de alcançar consumidores geograficamente distantes, a qualquer hora, seja por meio de vitrines virtuais, panfletos interativos, boletins on-line ou prestação de serviços (BOONE, 2006).

Segundo Tomikawa (2009, p. 64),

hoje, a internet possibilita ao turista acesso a informações amplas sobre seu objeto de turismo. Dessa forma, suas ações são cada vez mais direcionadas pela quantidade e qualidade das informações prestadas, sejam pelas operadoras de turismo ou órgãos governamentais responsáveis pelo desenvolvimento turístico de uma região.

Além dos websites administrados pelos municípios, a SETEL disponibiliza uma ferramenta importante para a comunicação de eventos em sua página na internet, onde os organizadores podem, gratuitamente, apresentar os eventos de forma detalhada ao seu público-alvo (SETUR/RS, 2015; SETEL/ RS, 2015).

Para este estudo, foram considerados os eventos que ocorreram na região central do Rio Grande do Sul em 2015, cadastrados para divulgação no website da SETEL. Ressalta-se que a iniciativa de cadastramento dos eventos é dos organizadores, de modo que os eventos que constam no referido website não representam a totalidade dos eventos realizados na região estudada (SETUR/RS, 2015; SETEL/RS, 2015). 
Quadro 5 - Eventos da região central do Rio Grande do Sul cadastrados no website da SETEL/ RS - 2015

\begin{tabular}{|c|c|c|}
\hline Município & Evento & Ocorrência \\
\hline Agudo & $18^{\mathrm{a}}$ Festa do Morango e da Cuca & Outubro \\
\hline $\begin{array}{l}\text { Cachoeira do } \\
\text { Sul }\end{array}$ & $2^{\mathrm{a}}$ Fenafest & Novembro \\
\hline \multirow{4}{*}{$\begin{array}{l}\text { Faxinal do } \\
\text { Soturno }\end{array}$} & $12^{\circ}$ Festival do Peixe e Feira do Peixe & Março \\
\hline & $\begin{array}{c}23^{\mathrm{a}} \text { Expofax, } 11^{\mathrm{a}} \text { Expocolônia e } 14^{\mathrm{a}} \text { Mostra do Gado } \\
\text { Leiteiro }\end{array}$ & Maio \\
\hline & $\begin{array}{c}2^{\text {a }} \text { Semana Cultural e Gastronômica e Semana Farrou- } \\
\text { pilha }\end{array}$ & Setembro \\
\hline & $10^{\circ}$ Natal Encanto e Luz & Dezembro \\
\hline $\begin{array}{l}\text { Júlio de Casti- } \\
\text { lhos }\end{array}$ & $54^{\mathrm{a}}$ Expojuc e $8^{\mathrm{a}}$ Expoarte & Outubro \\
\hline \multirow[t]{12}{*}{ Santa Maria } & $21^{\text {a }}$ Rodeio Internacional do Conesul & Março \\
\hline & Carnaval de Santa Maria 2015 & Março \\
\hline & $42^{\mathrm{a}}$ Feira do Livro de Santa Maria & Abril \\
\hline & Pátio Rural & Junho \\
\hline & $5^{\circ}$ Pátio Rural & Julho \\
\hline & $6^{\circ}$ Pátio Rural de Santa Maria & Setembro \\
\hline & $48^{\mathrm{a}}$ Expofeira Agropecuária de Santa Maria & Setembro \\
\hline & $19^{\text {a }}$ Mercocycle & Outubro \\
\hline & Expoaer & Outubro \\
\hline & Romaria Estadual Nossa Senhora Medianeira & Novembro \\
\hline & $23^{\text {a }}$ Tertúlia Musical Nativista & Novembro \\
\hline & Natal do Coração 2015 & Novembro \\
\hline \multirow[t]{5}{*}{ Santiago } & $27^{\mathrm{a}}$ Copa Santiago Internacional de Futebol Juvenil & Janeiro \\
\hline & $9^{\text {a }}$ Muamba Regional & Fevereiro \\
\hline & Carnaval Popular de Santiago & Fevereiro \\
\hline & $13^{\mathrm{a}}$ Encenação da Paixão e Morte de Cristo & Abril \\
\hline & $13^{\mathrm{a}}$ Fecoarti & Outubro \\
\hline $\begin{array}{l}\text { São Pedro do } \\
\text { Sul }\end{array}$ & $1^{\mathrm{a}}$ Feira de São Pedro & Abril \\
\hline \multirow{3}{*}{$\begin{array}{l}\text { São João do } \\
\text { Polesine }\end{array}$} & Romaria ao Monumento Nossa Senhora da Salete & Setembro \\
\hline & Natal Iluminado & Dezembro \\
\hline & Missa de Aniversário de João Luiz Pozzobon & Dezembro \\
\hline $\begin{array}{l}\text { São Vicente do } \\
\text { Sul }\end{array}$ & $\begin{array}{l}27^{\mathrm{a}} \text { Fecobat - Feira Estadual de Comércio da Batata } \\
\text { Doce }\end{array}$ & Julho \\
\hline
\end{tabular}

Fonte: elaborado pelos autores, a partir dos dados da SETUR/RS (2015) e da SETEL/RS (2015). 
Constatou-se que, dos 35 municípios que compõem a região, somente nove incluíram seus eventos no website da Secretaria de Turismo. Santa Maria destaca-se como o município que possui o maior número de eventos no referido website (12). Na sequência, encontra-se Santiago, com cinco; Faxinal do Soturno com quatro, São João do Polêsine com três e os demais municípios com somente um evento (Quadro 5). Considerando a totalidade de eventos que aconteceram nos municípios estudados no período analisado, percebe-se que a divulgação no website da SETEL é realizada somente por uma pequena parcela dos organizadores.

O período de ocorrência dos eventos analisados é mais concentrado nos meses de setembro, outubro e novembro, tendo, no segundo semestre, ocorrido grande parte dos eventos $(65 \%)$. Isso demonstra falta de planejamento do setor de turismo de eventos, pois a concentração acarreta sobreposição de eventos em um mesmo período de tempo, o que dificulta a atração de turistas e pulveriza a demanda.

A periodicidade da quase totalidade é anual, com exceção somente do evento denominado Pátio Rural, que ocorre em Santa Maria. Este quesito apresenta uma particularidade que pode ser utilizada pelos organizadores como uma oportunidade de proporcionar aos turistas experiências singulares para a demanda de outros produtos turísticos, além do evento, tais como a natureza, a gastronomia, os aspectos culturais e religiosos, entre outros.

Quadro 6 - Características dos eventos da região central do Rio Grande do Sul cadastrados na SETEL/RS - 2015

\begin{tabular}{|c|c|c|c|}
\hline Evento & Organizador & Tipo & Abrangência \\
\hline $\begin{array}{c}18^{\mathrm{a}} \text { Festa do Morango e da } \\
\text { Cuca }\end{array}$ & Prefeitura Municipal & $\begin{array}{l}\text { Gastronô- } \\
\text { mico }\end{array}$ & Estadual \\
\hline $2^{\mathrm{a}}$ Fenafest & Feira Nacional do Arroz & $\begin{array}{c}\text { Feiras e } \\
\text { exposições }\end{array}$ & Microrregional \\
\hline $\begin{array}{c}12^{\circ} \text { Festival do Peixe e Feira } \\
\text { do Peixe }\end{array}$ & Prefeitura Municipal & $\begin{array}{l}\text { Gastronô- } \\
\text { mico }\end{array}$ & Microrregional \\
\hline $\begin{array}{l}23^{\mathrm{a}} \text { Expofax, 11 }{ }^{\mathrm{a}} \text { Expocolônia } \\
\text { E } 14^{\mathrm{a}} \text { Mostra do Gado Leiteiro }\end{array}$ & Prefeitura Municipal & $\begin{array}{c}\text { Feiras e } \\
\text { exposições }\end{array}$ & Microrregional \\
\hline $\begin{array}{l}2^{\mathrm{a}} \text { Semana Cultural e Gastro- } \\
\text { nômica e Semana Farroupilha }\end{array}$ & Prefeitura Municipal & $\begin{array}{l}\text { Gastronômi- } \\
\text { co; Semana } \\
\text { Farroupilha } \\
\end{array}$ & Microrregional \\
\hline $10^{\circ}$ Natal Encanto E Luz & João Luiz Pozzobon & Religioso & Microrregional \\
\hline $54^{\mathrm{a}}$ Expojuc e $8^{\mathrm{a}}$ Expoarte & $\begin{array}{l}\text { Associação Cultural do } \\
\text { Comércio, Indústria e } \\
\text { Atividade Agropecuária } \\
\text { e Expojuc }\end{array}$ & $\begin{array}{l}\text { Feiras e } \\
\text { exposições }\end{array}$ & Estadual \\
\hline $\begin{array}{c}21^{\mathrm{a}} \text { Rodeio Internacional do } \\
\text { Conesul }\end{array}$ & $\begin{array}{c}\text { Associação Tradicio- } \\
\text { nalista Estância do } \\
\text { Minuano } \\
\end{array}$ & $\begin{array}{l}\text { Rodeio } \\
\text { crioulo }\end{array}$ & Internacional \\
\hline Carnaval de Santa Maria & Prefeitura Municipal & Carnaval & Microrregional \\
\hline $\begin{array}{c}42^{\mathrm{a}} \text { Feira do Livro de Santa } \\
\text { Maria }\end{array}$ & $\begin{array}{c}\text { Prefeitura Municipal, } \\
\text { Câmara do Livro, CES- } \\
\text { MA, UFSM, UNIFRA e } \\
8^{\text {a }} \text { Coordenadoria Regio- } \\
\text { nal de Educação }\end{array}$ & $\begin{array}{c}\text { Feiras e } \\
\text { exposições; } \\
\text { Cultural }\end{array}$ & Microrregional \\
\hline Pátio Rural & Prefeitura Municipal & $\begin{array}{l}\text { Gastronô- } \\
\text { mico }\end{array}$ & Microrregional \\
\hline
\end{tabular}




\begin{tabular}{|c|c|c|c|}
\hline Evento & Organizador & Tipo & Abrangência \\
\hline $5^{\circ}$ Pátio Rural & Prefeitura Municipal & $\begin{array}{l}\text { Gastronô- } \\
\text { mico }\end{array}$ & Microrregional \\
\hline $6^{\circ}$ Pátio Rural de Santa Maria & Prefeitura Municipal & $\begin{array}{l}\text { Gastronô- } \\
\text { mico }\end{array}$ & Microrregional \\
\hline $\begin{array}{c}48^{\mathrm{a}} \text { Expofeira Agropecuária de } \\
\text { Santa Maria }\end{array}$ & $\begin{array}{l}\text { Associação Rural de } \\
\text { Santa Maria }\end{array}$ & $\begin{array}{c}\text { Feiras e } \\
\text { exposições }\end{array}$ & Estadual \\
\hline $19^{\mathrm{a}}$ Mercocycle & Gaudérios do Asfalto & Esportivo & Internacional \\
\hline Expoaer & $\begin{array}{c}\text { Base Aérea de Santa } \\
\text { Maria }\end{array}$ & $\begin{array}{c}\text { Feiras e } \\
\text { exposições }\end{array}$ & Microrregional \\
\hline $\begin{array}{c}\text { Romaria Estadual Nossa Se- } \\
\text { nhora Medianeira }\end{array}$ & $\begin{array}{l}\text { Arquidiocese de Santa } \\
\text { Maria }\end{array}$ & Religioso & Estadual \\
\hline $23^{\mathrm{a}}$ Tertúlia Musical Nativista & Prefeitura Municipal & $\begin{array}{l}\text { Gastronô- } \\
\text { mico }\end{array}$ & Microrregional \\
\hline Natal do $\mathrm{C}$ & $\begin{array}{c}\text { Prefeitura Municipal e } \\
\text { Câmara de Dirigentes } \\
\text { Lojistas }\end{array}$ & Religioso & Es \\
\hline $\begin{array}{c}27^{\mathrm{a}} \text { Copa Santiago Internacio- } \\
\text { nal De Futebol Juvenil }\end{array}$ & $\begin{array}{c}\text { Cruzeiro Esporte Clube } \\
\text { de Santiago }\end{array}$ & Esportivo & Internacional \\
\hline $9^{\text {a }}$ Muamba Regional & Prefeitura Municipal & Carnaval & Microrregional \\
\hline Carnaval Popular de Santiago & Prefeitura Municipal & Carnaval & Microrregional \\
\hline $\begin{array}{c}13^{\text {a }} \text { Encenação da Paixão e } \\
\text { Morte de Cristo }\end{array}$ & Prefeitura Municipal & Religioso & Microrregional \\
\hline $13^{\mathrm{a}}$ Fecoarti & $\begin{array}{c}\text { Centro Empresarial de } \\
\text { Santiago }\end{array}$ & $\begin{array}{c}\text { Feiras e } \\
\text { exposições }\end{array}$ & Estadual \\
\hline $1^{a}$ Feira de São Pedro & Prefeitura Municipal & $\begin{array}{c}\text { Feiras e } \\
\text { exposições }\end{array}$ & Estadual \\
\hline $\begin{array}{l}\text { Romaria ao Monumento Nossa } \\
\text { Senhora da Salete }\end{array}$ & $\begin{array}{c}\text { Paróquia São João } \\
\text { Batista } \\
\end{array}$ & Religioso & Local \\
\hline Natal Iluminado & Prefeitura Municipal & Religioso & Local \\
\hline $\begin{array}{c}\text { Missa de Aniversário de João } \\
\text { Luiz Pozzobon }\end{array}$ & $\begin{array}{l}\text { Polo João Luiz Pozzo- } \\
\text { bon }\end{array}$ & Religioso & Microrregional \\
\hline $\begin{array}{l}27^{\text {a }} \text { Fecobat - Feira Estadual de } \\
\text { Comércio da Batata Doce }\end{array}$ & Prefeitura Municipal & $\begin{array}{c}\text { Feiras e } \\
\text { exposições }\end{array}$ & Estadual \\
\hline
\end{tabular}

Fonte: elaborado pelos autores a partir dos dados da SETUR/RS (2015) e da SETEL/RS (2015). 
Os eventos divulgados foram categorizados pela tipologia de atrações: nove (32\%) foram cadastrados como feiras e exposições, sete $(24 \%)$ como eventos gastronômicos, sete $(24 \%)$ como eventos religiosos, três $(10 \%)$ como atividades relacionadas ao carnaval, dois $(7 \%)$ como eventos esportivos e um (3\%) como atrações referentes à cultura gaúcha (rodeio crioulo). Classificados como de abrangência internacional estão os seguintes eventos: $27^{\mathrm{a}}$ Copa Santiago Internacional de Futebol Juvenil, no município de Santiago, $21^{\text {a }}$ Rodeio Internacional do Conesul e $19^{\text {a }}$ Mercocycle, ambos em Santa Maria. Dentre os demais eventos, oito são estaduais, 16 são microrregionais e dois são locais (Quadro 6).

Quanto à organização, verificouse que a maioria dos eventos é realizada pelas Prefeituras Municipais (53\%). Alguns são realizados em parceria entre o poder público e as entidades privadas $(7 \%)$, e $40 \%$ são organizados por instituições privadas, tais como: Paróquia São João Batista de São João do Polêsine, Arquidiocese de Santa Maria, Associação Tradicionalista Estância do Minuano de Santa Maria, Base Aérea de Santa Maria, Associação Rural de Santa Maria e Cruzeiro Esporte Clube de Santiago (Quadro 6).

\section{Considerações finais}

A análise da região central do Rio Grande do Sul, sob o escopo do setor de turismo, considerando a categorização dos municípios realizada pelo Ministério do Turismo Brasileiro, demonstrou que a região está muito abaixo da média brasileira e gaúcha, o que indica que o setor ainda tem pouca representatividade no desempenho econômico e tem potencialidades a serem exploradas.

No detalhamento relacionado aos eventos, verificou-se que na região estudada predominam as feiras e exposições e os eventos gastronômicos e religiosos, organizados pelas Prefeituras $\mathrm{Mu}-$ nicipais, isoladamente ou em conjunto com entidades de classe, e apresentando abrangência microrregional. Os resultados indicam uma carência de diversidade na tipologia dos eventos realizados, que, segundo Getz (2008), podem ter uma grande variedade de propósitos e de programação e, consequentemente, contribuir na atração de uma quantidade maior de turistas para a região.

$\mathrm{Na}$ pesquisa realizada com o intuito de verificar quais eventos da região central estão sendo divulgados no website da SETEL, constatou-se uma subutilização dessa importante ferramenta gratuita de divulgação e atração de turistas por parte dos organizadores de eventos e, principalmente, das Prefeituras Municipais da região analisada. A baixa utilização do website foi percebida com base em dois aspectos: (a) a maioria das Prefeituras Municipais (74\%) e dos organizadores privados da região não cadastram os eventos que organizam; e (b) as Prefeituras que cadastram divulgam somente alguns eventos realizados.

Considerando um processo eficaz de marketing turístico e a relevância do uso da internet na atualidade para divulgação de produtos e serviços, particularmente no segmento de turismo de eventos, percebe-se que há baixa proatividade dos organizadores e do setor público para a divulgação dos eventos, principalmente considerando que a divulgação no website da Secretaria de Turismo é gratuita. Tal constatação está em descordo com os achados de estudiosos que reforçam: (a) a importância da disponibilização ampla de informações para auxiliar no processo de decisão de compra (KOTLER e KEPLER, 2012; HOFFMANN e BATSON, 2006; BOONE e KURTZ, 2009); (b) a necessidade de utilização plena da comunicação para atração de consumidores/turistas (HOFFMANN e BATSON, 2006; SHIMP, 2010; URDAN e URDAN, 2009); e (c) a relevância do uso da internet com o intuito de proporcionar praticidade, rapidez e interatividade em uma abrangência geográfica ilimitada 
(TORRES, 2010; BOONE, 2006 e TOMIKAWA, 2009).

Em resumo, pode-se inferir que a região central tem condições de ampliar a participação do setor de turismo em sua atividade produtiva, com reflexos positivos no desempenho econômico e social, desde que reconheça a importância da aproximação com os turistas e a profissionalização na divulgação e prestação dos serviços ofertados no campo do turismo de eventos. A necessidade de incremento da atividade turística é consolidada pela relevância do setor no contexto nacional. Segundo o Ministério do Turismo, a participação do turismo no PIB brasileiro, em 2014, foi de 3,5\% (R \$ 182 bilhões) e, entre os anos de 2003 e 2009, apresentou uma expansão de $24,6 \%$. A estimativa do Ministério é de que o setor será responsável pela criação de 10,59 milhões de empregos diretos e indiretos no ano de 2023, o que representará aproximadamente $9,5 \%$ do total de empregos no país (BRASIL, 2016).

Para o sucesso de um evento, é importante o planejamento e a execução adequada. Como cada evento é único, suas interações com o ambiente, os participantes, o público e o próprio sistema de organização necessitam ser bem desenhadas pela equipe profissional, envolvendo turismólogos, profissionais das relações públicas, jornalistas, e gestores de eventos, por exemplo, considerando que um dos principais apelos de um evento é a ideia de se estar vivendo uma experiência única, não repetível.

Dessa maneira, entidades locais, regionais e estaduais deveriam tornar-se partes interessadas nos eventos turísticos, principalmente pelo potencial que eles têm em atrair visitantes e, assim, aumentar os seus gastos nas localidades, bem como pela capacidade que os eventos têm de aumentar o conhecimento acerca da região e de acolher novas atividades turísticas.

Por fim, também é necessário que mais estudos sejam feitos para que se ob- tenham maiores subsídios que embasem as práticas de gestão em turismo, em especial, a gestão de eventos turísticos. Somente com sólidos conhecimentos, gestão pública comprometida e consequente participação comunitária, as potencialidades do turismo de eventos realizar-se -ão, gerando reflexos positivos no desenvolvimento econômico, social e cultural dos locais em que são realizados.

\section{Referências}

ALLEN, J.; MCDONALD, I.; WILLIAM, O. Organização e Gestão de Eventos. São Paulo: Campus, 2003.

BAHL, M. Turismo e Eventos. Curitiba: Protexto, 2004.

BARBOSA, Fabrício Silva; SCAVARDA, Anníbal José. Um modelo conceitual de megaeventos musicais. CULTUR - Revista de Cultura e Turismo, ano $09, n^{\circ} 02$, p. 135-150, Jun./2015.

BARRETTO, M. Turismo e Legado Cultural: as possibilidades do planejamento. Campinas: Papirus, 2000.

BOONE, L.E; KURTZ, D.L. Marketing Contemporâneo. São Paulo: Centage Learning, 2009.

BRASIL. MINISTÉRIO DO TURISMO. Disponível em http://www.turismo.gov.br. Acesso em 06/06/2015.

CARDOSO, Margarida Lopes. A Importância da Organização de Eventos no Turismo. Porto, 2013. Dissertação (Mestrado em Turismo) - Faculdade de Letras, Universidade do Porto.

DaCOSTA, L. P. et al. (Ed.). Legados de Megaeventos Esportivos. Brasília: Ministério do Esporte, 2008.

GETZ, Donald. Event tourism: Definition, evolution and research. Tourism Management, $\mathrm{n}^{\circ}$ 29, pp. 403-428, 2008.

GETZ, Donald. O evento turístico e o 
dilema da autenticidade. In: THEOBALD, William F. (Org.). Turismo global. São Paulo: Senac, 2001, p. 423440 .

HOFFMANN, K.D.; BATSON, J.E.G. Princípios de marketing de serviços. São Paulo: Pioneira Thomson Learning, 2006.

HORNE, J; MANZENREITER, W. (Ed.). Sports Mega-Events: Social Scientific Analyses of a Global Phenomenon. Oxford, UK: Blackwell Publishing Ltd., 2006.

KOTLER, Philip. Administração de Marketing. $10^{\mathrm{a}}$ ed. São Paulo: Prentice Hall, 2000.

KOTLER, Philip; ARMSTRONG, Gary. Princípios de Marketing. $9^{\mathrm{a}}$ ed. São Paulo: Prentice Hall, 2003.

KOTLER, Philip; KELLER, Kevin L. Marketing Management. $4^{\text {a }}$ ed. New Jersey: Pearson Education, 2012.

MARUJO, Noémi. O contributo do turismo de eventos para o desenvolvimento turístico de uma região. DELOS: Desarrollo Local Sostenible, vol. 8, n. 23, p.1-15, jun./ 2015.

MARUJO, Noémi. Tourism and special events: the Flower Festival in Madeira Island. Tourism \& Management Studies, vol. 10, n⿳⺈ 2, p. 26-31, 2014.

MATIAS, M. Organização de eventos: procedimentos e técnicas. $5^{\mathrm{a}}$ ed. Barueri: Manole, 2010.

MATTAR, F.N. Pesquisa de Marketing. São Paulo: Atlas, 1996.

MEIRELLES, G.F. Tudo sobre Eventos. São Paulo: STS, 2009.

MONTEJANO, J.M. Estrutura do mercado turístico. São Paulo: Roca, 2001.

RIO GRANDE DO SUL. Plano de Desenvolvimento do Turismo do Rio Grande do Sul: 2012-2015. Rio de Janeiro: FGV Projetos, 2012.
RUSCHMANN, D. Turismo e planejamento sustentável: a proteção do meio ambiente. São Paulo: Papirus, 2000.

SETEL/RS. Disponível em http://www. setel.rs.gov.br. Acesso em 06/06/2015.

SETUR/RS. Secretaria de Turismo do Rio Grande do Sul. Disponível em http://www.turismo.rs.gov.br. Acesso em 06/06/2015.

SHIMP, T. Propaganda e promoção: aspectos complementares da comunicação integradas de marketing. Porto Alegre: Bookmann, 2010.

SMALL, Katie Elizabeth. Understanding the Social Impacts of Festivals on Communities. Sydney, 2007. Tese (Doutorado) - University of Western Sydney.

TOMIKAWA, J. M. Marketing turístico e internet: uma análise dos sites oficiais de turismo dos estados brasileiros. Brasília, 2009. Dissertação (Mestrado em Turismo) - Centro de Excelência em Turismo, Universidade de Brasília.

TORRES, C. Marketing na internet. 2010. Disponível em http://www. claudiotorres.com.br/mktdigitalpequenaempresa.pdf. Acesso em 15/10/2015.

URDAN, F.T.; URDAN, A.T. Gestão do composto de marketing. São Paulo: Atlas, 2006.

ZANELLA, L.C. Manual de organização de eventos: planejamento e organização. São Paulo: Atlas, 2004. 